\title{
Biomechanical study of strength and stiffness of the knee anterolateral ligament
}

\author{
Camilo Partezani Helito ${ }^{1,4^{*}}$, Marcelo Batista Bonadio ${ }^{1}$, João Stefan Rozas ${ }^{3}$, João Marcelo Pedroso Wey ${ }^{3}$, \\ Cesar Augusto Martins Pereira², Tulio Pereira Cardoso³, José Ricardo Pécora', Gilberto Luis Camanho' \\ and Marco Kawamura Demange ${ }^{1}$
}

\begin{abstract}
Background: Recent studies clearly characterize the anatomical parameters of the knee anterolateral ligament (ALL). The potential clinical importance of this ligament is exemplified by some patients with possible combined Anterior Cruciate Ligament (ACL) and $\mathrm{ALL}$ rupture who do not progress satisfactorily following isolated $\mathrm{ACL}$ reconstruction. Previous biomechanical studies have assessed the resistance parameters of the ALL in order to address potential reconstruction strategies; however, these have reported conflicting results. Thus, this study aimed to evaluate the linear resistance of the ALL by means of a biomechanical study in cadaveric knees.
\end{abstract}

Methods: Fourteen cadaveric knees were used. The ALL was dissected, and all structures that connect the femur and the tibia, except for the ALL, were sectioned. The ALL was subjected to a tensile test with the knee around 30 to 40 degrees, in a way that the ALL was aligned with the machine. The strength at the maximum resistance limit, deformation and stiffness of the ALL were evaluated.

Results: The mean maximum strength of the ALL was $204.8+/-114.9 \mathrm{~N}$. The stiffness was $41.9+/-25.7 \mathrm{~N} / \mathrm{mm}$ and the deformation $10.3+/-3.5 \mathrm{~mm}$.

Conclusion: The ALL has a mean ultimate tensile strength of $204.8 \mathrm{~N}$. This suggests that simple bands of all autologous or homologous grafts commonly used in clinical practice for ligament reconstruction around the knee possess the required biomechanical resistance characteristics for ALL reconstruction.

Keywords: Knee, Anterolateral ligament, Biomechanics, Anatomy

\section{Background}

Recent studies have characterized the anterolateral ligament (ALL) of the knee in detail [1-6]. This structure is regarded as having a complementary action to the anterior cruciate ligament (ACL) with regard to anterolateral rotational knee stability. Its potential clinical importance is exemplified by patients with possible combined ACL and ALL rupture who do not progress satisfactorily following isolated ACL reconstruction $[7,8]$.

\footnotetext{
* Correspondence: Camilo_helito@yahoo.com.br

The study was performed at the Department of Orthopedics and

Traumatology, Faculty of Medicine, University of São Paulo, São Paulo, Brazil.

${ }^{1}$ Knee Surgery Division, Department of Orthopaedics and Traumatology, Institute of Orthopedics and Traumatology-Hospital and Clinics, Faculty of Medicine, University of São Paulo (IOT-HCFMUSP), São Paulo, Brazil

${ }^{4}$ Rua Dr. Ovídio Pires de Campos, 333, Cerqueira Cesar, São Paulo SP CEP:

05403-010, Brazil

Full list of author information is available at the end of the article
}

Anatomical and histological studies have confirmed the presence of the ALL and showed well-organized dense connective tissue in the ALL substance, compatible with true ligament tissue. These findings have been corroborated by imaging studies of the ALL $[4,6,9,10]$. Despite some controversy regarding femoral attachment, which has already been defined as anterior and distal or posterior and proximal to the Lateral Collateral Ligament (LCL), the tibial attachment between Gerdy's tubercle and the fibular head is constant. Similar to the medial side, a meniscal attachment at the transition between the anterior horn and the meniscus body has been found [3, 4, 6, 11]. Radiographic landmarks and length change patterns of the ligament during flexionextension were also studied [12-14].

Biomechanical studies that tested the anterolateral capsule and indirectly demonstrated the importance of 
the ALL to rotatory knee stability were conducted, and Zens et al. and Kennedy et al. tested the tensile properties of this ligament [15-18]. Despite using similar methods, these two biomechanical studies reported substantially different resistance characteristics of the ALL. This poses difficulty in creating appropriate reconstruction techniques that rely on such studies to define both the graft and fixation method to be used $[17,18]$.

Knowledge of the ligament's tensile properties may contribute to a better understanding of the ligament's behavior, allowing for a fact-based assessment of its contribution to knee stability. This is essential for the selection of suitable transplant and reconstruction techniques. Thus, the present study aimed to evaluate the linear resistance of the ALL by means of biomechanical tests in cadaveric knees.

\section{Methods}

For this study, 14 unpaired knees from male fresh-frozen cadavers were used. The mean age was $62.6+/-8.38$ (range from 49 to 77). Before testing, the specimens were thawed for $24 \mathrm{~h}$. All tests were performed at room temperature and the specimens were constantly kept moist with saline solution. The study was conducted following approval from the ethics committee at our institution. Consent was given either during life or from the next of kin following death for the use of cadavers in scientific research.

The ALL was dissected in a standard manner from all cadavers used. The protocol used for dissection has already been described in previous studies [2-4]. Initially, the skin and subcutaneous tissue were dissected, followed by tenotomy of the quadriceps tendon in its myotendinous junction, medial parapatellar opening of the retinaculum and osteotomy of the anterior tibial tuberosity to access the anterolateral region of the knee without violating adjacent extra-articular soft tissue. The retropatellar fatpad was partially removed in order to create better vision. The entire iliotibial tract was cut approximately $5 \mathrm{~cm}$ proximal to the lateral epicondyle and then reflected and detached from Gerdy's tubercle and surrounding areas. The biceps tendon was cut immediately proximal to the fibular head. Biceps expansions to the tibia were also carefully removed. The popliteus muscle tendon (PT) and the LCL were carefully isolated so as not to reach the ALL attachment on the lateral epicondyle.

After these structures were isolated, capsular thickening could be clearly observed in the anterolateral region of the knee, which is consistent with the ALL, especially when performing flexion and internal rotation of the tibia. Starting at the femoral origin, the dissection was performed from the proximal to the distal region until the tibial insertion was isolated (Fig. 1).

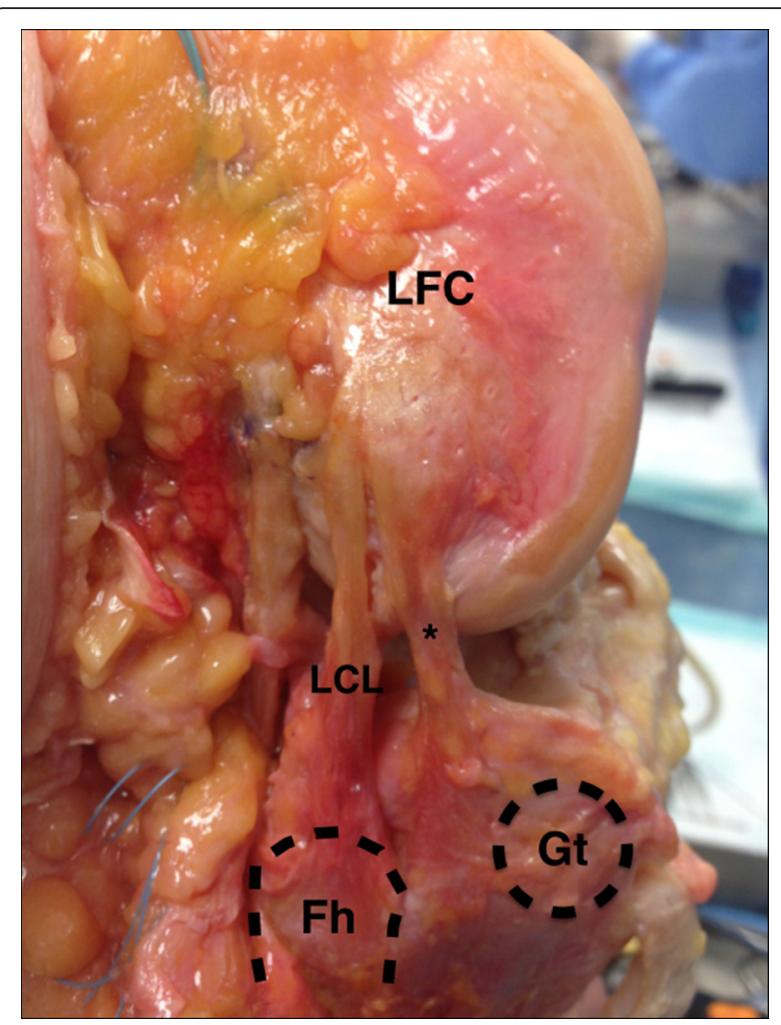

Fig. 1 Lateral view of a right knee showing the anatomical features of the knee anterolateral ligament (asterisk). LFC - Lateral Femoral Condyle, LCL - Lateral Colateral Ligament, Fh - Fibular head, Gt Gerdy's tubercle

After isolating the ALL, all intra-articular and peripheral structures of the knee were sectioned, and only the ALL remained intact on the lateral portion of the knee, which was the only remaining structure connecting the femur and the tibia.

The ligaments were subjected to a tensile test using a Kratos 5002 universal biomechanical test machine (Kratos Dynamômetros, São Paulo, Brazil), with a $100-\mathrm{kgf}$ load cell, adjusted in a $20 \mathrm{kgf}$ scale, with a crosshead speed of $20 \mathrm{~mm} / \mathrm{min}$. The force and deformation parameters from the testing machine were recorded on the computer through a system of ADS 2000 data acquisition 14 -bit resolution (Lynx Electronic Technology Ltda, São Paulo, Brazil) and a program written in Delphi 2006 (Borland software Corporation, Austin - Texas, USA), using the acquisition routines provided by the manufacturer of the acquisition system.

The bone portions of the knee were connected to the machine with two tubular clips with radial screws, with one clip fixing the femur and one clip fixing the tibia. The femur was kept in the proximal region and the tibia in the distal region of the assembly, maintaining the tibial axis visually in alignment with the machine axis. In 
the assembly, the tibial tubular clip was fixed at the base of the machine using a bench vise, allowing only proximal displacement of the femur, which was attached to the moving part of the machine. The test was performed with the knee in approximately 30 to 40 degrees of flexion, such that the ALL was aligned with the machine (Fig. 2).

The parameters analyzed were strength at maximum ligament resistance limit, expressed in Newtons, and stiffness, defined as the ratio of the differences of strength and deformation between two points in the linear region of the strength versus deformation diagram, expressed in $\mathrm{N} / \mathrm{mm}$.

\section{Results}

The ALL was found in all knee dissections. Its circular shape femoral attachment was anterior and distal to the LCL main attachment in 12 cases and immediately anterior in two cases. As the main insertion of the LCL is posterior and proximal to the lateral epicondyle as described by LaPrade et al., the ALL insertion was close to the lateral epicondyle center [19]. The band-shaped tibial attachment was found between Gerdy's tubercle and the fibular head, around 5 to $10 \mathrm{~mm}$ distal to the lateral plateau.

The mean maximum strength of the ALL in the cases studied was $204.8+/-114.9 \mathrm{~N}$ (Fig. 3). The mean stiffness was $41.9+/-25.7 \mathrm{~N} / \mathrm{mm}$ (Table 1 ).
In 10 knees, ligament failure was caused by stretching of the ligament body fibers, or midsubstance tears. In two cases the ALL was detached from its femoral origin and in one case it was detached from its tibial origin. Finally, in one case a distal tibia attachment avulsion fracture ("Segond fracture") occurred. There were no cases of femoral avulsion fractures. The deformation of ALL at the breaking point was $10.3+/-3.5 \mathrm{~mm}$, around $30 \%$ of the ligament total length.

\section{Discussion}

In the present study, the ALL had a maximum mean strength of $204.8 \mathrm{~N}$ and a mean stiffness of $41.9 \mathrm{~N} / \mathrm{mm}$. These findings are important because they enable the selection of adequate grafts and fixation methods for possible reconstructions of the ALL associated with reconstructions of the ACL.

Although there are no specific indications in the literature for ALL reconstruction, several authors have published suggestions for extra-articular reconstruction associated with intra-articular ACL reconstruction. Revision cases or athletes with high pivot-shift scores on the preoperative assessment are possible candidates [20-26]. The ALL reconstruction would involve an extra-articular reconstruction technique, but respecting the anatomical parameters of this structure in the anterolateral region of the knee [1-6]. Some classical extra-articular reconstruction procedures

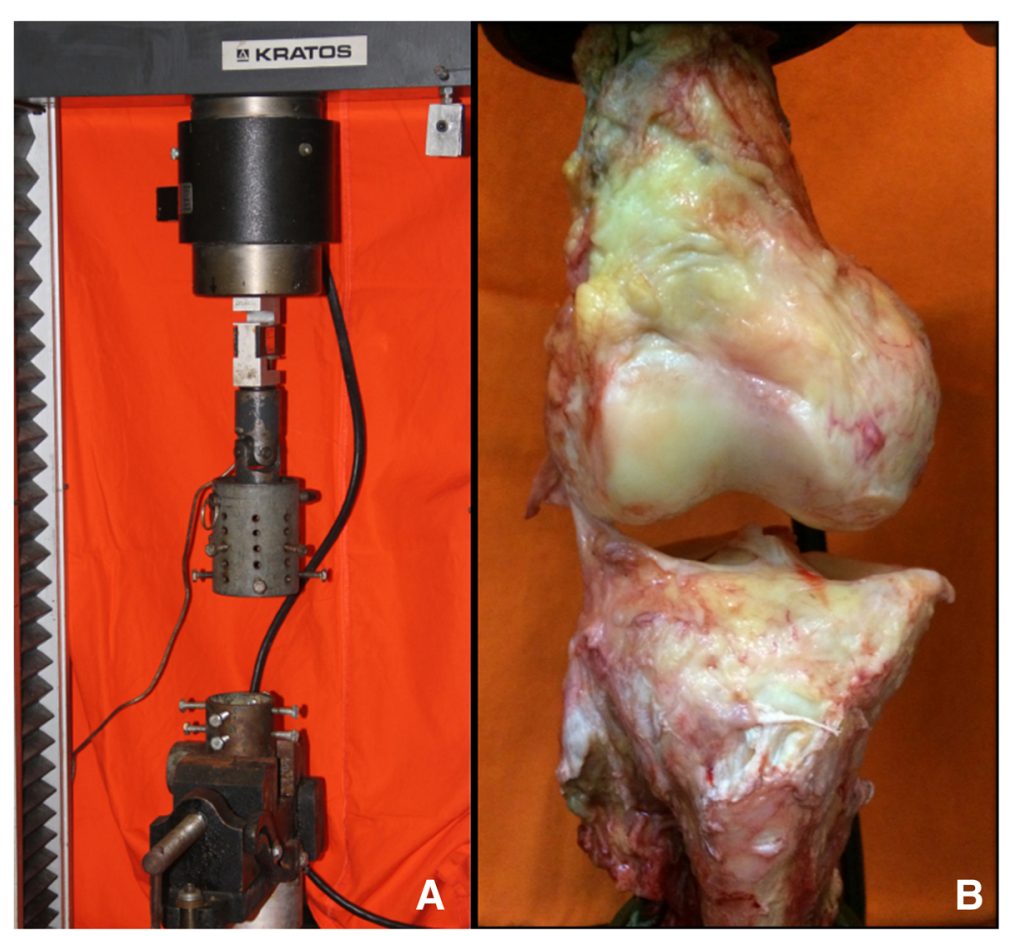

Fig. 2 Picture showing the Kratos machine used to perform the biomechanical tests (a) and the dissected knee with only the Anterolateral Ligament connecting the femur to the tibia being tested (b) 


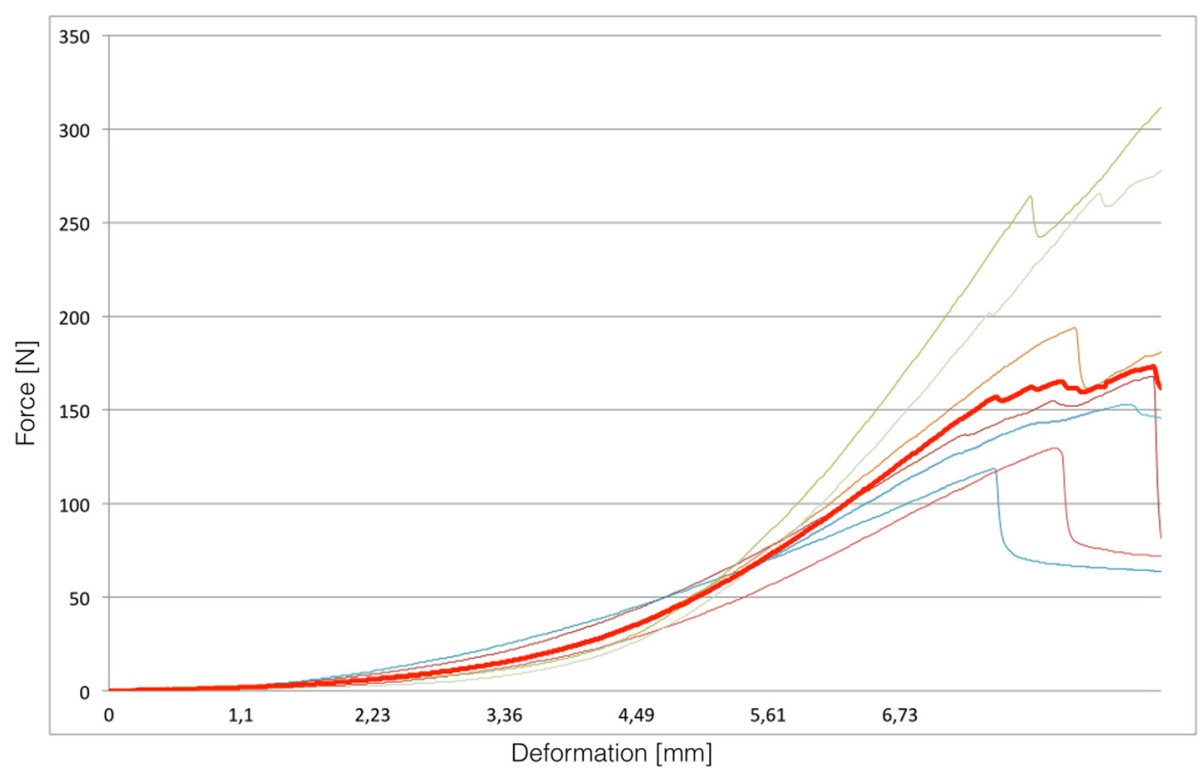

Fig. 3 Graphic showing strength $(\mathrm{N})$ and deformation $(\mathrm{mm})$ examples of the knee anterolateral ligament (the red line is the average of studied knees). Not all samples are showed in the graphic

reroute a strip of the iliotibial tract deep to the LCL in order to reconstruct the ACL. However, due to the extra-articular position, these reconstructions merely focus on controlling internal tibial rotation and only have limited capacity reducing anterior tibial translation [24].
According to the values measured, the ALL exhibits maximum strength values similar to those of the medial patellofemoral ligament (MPFL) and lower than those of other medial and lateral peripheral ligaments of the knee [27-30]. According to studies by Mountney et al. and Herbort et al., the MPFL had a maximum strength of

Table 1 Knee data and Anterolateral Ligament biomechanical properties and failure mechanisms

\begin{tabular}{|c|c|c|c|c|}
\hline Knee & Age (years) & Load to failure $(\mathrm{N})$ & Stiffness (N/mm) & Mechanism of failure \\
\hline 1 & 54 & 168.04 & 37.96 & Midsubstance tears \\
\hline 2 & 71 & 114.60 & 23.68 & Midsubstance tears \\
\hline 3 & 56 & 327.12 & 36.62 & Midsubstance tears \\
\hline 4 & 68 & 118.57 & 25.25 & Midsubstance tears \\
\hline 5 & 54 & 193.77 & 45.38 & Tibial detachment \\
\hline 6 & 71 & 129.62 & 32.59 & Midsubstance tears \\
\hline 7 & 56 & 264.17 & 85.51 & Midsubstance tears \\
\hline 8 & 61 & 152.93 & 34.20 & Midsubstance tears \\
\hline 9 & 62 & 384.30 & 96.76 & Midsubstance tears \\
\hline 10 & 68 & 363.88 & 47.44 & Midsubstance tears \\
\hline 11 & 59 & 49.38 & 14.41 & Femoral detachment \\
\hline 12 & 77 & 145.72 & 18.08 & Segond fracture \\
\hline 13 & 71 & 371.70 & 71.58 & Midsubstance tears \\
\hline 14 & 49 & 83.01 & 17.26 & Femoral detachment \\
\hline Average & 62.6 & 204.8 & 41.9 & \\
\hline Median & 61.5 & 160.5 & 35.4 & \\
\hline Standard Deviation & 8.4 & 114.9 & 25.7 & \\
\hline Maximun & 77 & 384.30 & 96.76 & \\
\hline Minimun & 49 & 49.38 & 14.41 & \\
\hline
\end{tabular}


$208 \mathrm{~N}$ and $190.7 \mathrm{~N}$, respectively [28, 29]. Wijdicks et al. reported a strength of $557 \mathrm{~N}$ for the superficial medial collateral ligament, and Ciccone II et al. reported a maximum strength of $460 \mathrm{~N}$ for the LCL [27, 30]. According to our measured values, the ALL has maximum strength values lower than half of these collateral structures, which suggests that the ALL may not be the only important structure in restraining rotational knee laxity and is probably associated with the ACL and other lateral structures to perform this role [31].

The present study found a similar maximum strength of the ALL compared to Kennedy et al. [18], and a higher mean maximum strength compared to Zens et al. $(50 \mathrm{~N})$ [17]. Zens et al. found interligamentous tears in four cases, while Kennedy et al. observed four midsubstance tears, six Segond fractures, four femoral tears at the femoral origin and one tear at tibial origin. Most of our cases failed at the ALL body, similar to the results found by Zens et al., but we had four variations. The cases in which the failure happened as a femoral detachment presented the lower stress values (49 and $83 \mathrm{~N}$ ), well below the average found. None of the studies showed a femoral avulsion fracture. Even though the specimens ages differed among the three studies (Zens et al -86.5 years, Kennedy et al -58.2 years, current study - 62.6), the differences in maximum load at failure found cannot be credited to this fact, as suggested by Zens et al. This study found a higher age and a higher value for the ALL strength than Kennedy et al. A possible explanation for the lower results in the study by Zens at al. may be due to weakening of the ligament during dissection in order to completely isolate it.

Regarding grafts that could be used in possible reconstructions of this structure, based on the ALL strength and according to biomechanical tests performed by Pearsall IV et al. and Noyes et al. [32, 33], simple semitendinosus $(1216 \mathrm{~N})$, simple gracilis $(838 \mathrm{~N})$, a strip of the iliotibial tract, or even anterior tibial, posterior tibial or long peroneal tissue bank grafts would be suitable. The possibility of using only the simple semitendinosus or the simple gracilis would facilitate a combined reconstruction of the ALL and the ACL. The ACL graft could be composed of the triple semitendinosus with a simple gracilis, for example. The remaining portion of the gracilis would then be used for the ALL reconstruction $[34,35]$. Similar to the MPFL, there is no available graft for reconstruction which exactly mimics the tensile properties of the ALL. Thus, it seems important to pay close attention to positioning and tensioning of the graft in order to avoid over-constraining of the lateral compartment [31, 36]. Even with combined ALL reconstruction, studies have shown that the ACL diameter should be at least $8 \mathrm{~mm}$ to minimize failures in the intra-articular reconstruction [37].
Regarding graft fixation, biomechanical tests are still necessary to evaluate which technique is best for the repair or reconstruction of the ALL. Considering it shows strength values similar to those of the MPFL, it is possible to infer that ALL fixation using anchors will produce suitable functional clinical results. However, according to biomechanical studies, fixation with interference screws is more resistant [38]. The use of anchors for fixation would avoid creating one more bone tunnel in addition to the ACL tunnel, which would avoid the convergence problem that exists, for example, in combined reconstructions of the ACL and the posterolateral corner structures [39, 40]. Furthermore, because of the anatomical proximity between the ALL and the LCL, a lateral tunnel at the anatomical point of the ALL could cause an iatrogenic injury of the femoral insertion site of the LCL [1-6, 41].

Despite some differences in descriptions and controversies in the current literature [42-44], Claes et al. [42] suggested the Segond fracture as a result of an avulsion of the ALL in a study using anatomy and magnetic resonance imaging. Kennedy et al., using similar methodology, found most of the failures occurred because of a Segond fracture [18]. In the present study, we could reproduce only one case of failure due to tibial bone avulsion of the ALL. This may have occurred because of the linear tensile testing setup rather than a real life ACL injury.

This study is important because it characterizes the biomechanical resistance of the ALL. Despite the findings described, there is no clear indication for ALL reconstruction because neither its biomechanical importance to rotational stability nor its healing potential after injury is fully defined.

This study presented some limitations, such as the number of cadavers used for biomechanical testing, the fact that we only tested the ALL with an axial tensile testing setup and neutral rotation, the use of only male cadaver knees and the advanced age of the knees studied. We are also assuming that the freshfrozen cadavers utilized in this study exhibit similiar biomechanical properties as tissue in vivo. Due to the ALL connections to the LCL and adjacent structures, it is possible that in some cases a small portion of the ALL could also be removed, which may alter its biomechanical characteristics.

\section{Conclusions}

The ALL has a mean ultimate tensile strength of $204.8 \mathrm{~N}$. This suggests that simple bands of all autologous or homologous grafts commonly used in clinical practice for ligament reconstruction around the knee possess the required biomechanical resistance characteristics for ALL reconstruction. 


\section{Ethics and consent to participate}

The study was approved by the scientific committee of the Institute of Orthopedics and Traumatology, University of São Paulo, Brazil.

\section{Consent to publish \\ Not applicable.}

\section{Availability of data and materials}

All the data that supports this study is contained within the manuscript. Requests for further detail on the dataset and queries relating to data sharing arrangements may be submitted to the corresponding author.

\section{Abbreviations \\ ACL: anterior cruciate ligament; ALL: anterolateral ligament; LCL: lateral collateral ligament; MPFL: medial patellofemoral ligament; PT: popliteus muscle tendon.}

\section{Competing interests}

The authors declare that they have no competing interests.

\section{Author's contribution}

$\mathrm{CPH}, \mathrm{MBB}, \mathrm{TPC}, \mathrm{JRP}, \mathrm{GLC}$ and MKD designed and elaborated the study. CPH, $M B B, J S R$, JMPH and CAMP performed dissection and the biomechanical tests. $C P H, C A M P$ analyzed the data. $C P H, M B B$ and MKD wrote the manuscript. MKD, TPC, GLC and JRP supervised the study. All authors read and approved the final manuscript.

\section{Acknowledgements}

Nothing to declare.

\section{Funding}

No funding was obtained.

\section{Author details}

${ }^{1}$ Knee Surgery Division, Department of Orthopaedics and Traumatology, Institute of Orthopedics and Traumatology-Hospital and Clinics, Faculty of Medicine, University of São Paulo (IOT-HCFMUSP), São Paulo, Brazil. ${ }^{2}$ Biomechanical Laboratory Division, Department of Orthopaedics and Traumatology, Institute of Orthopedics and Traumatology-Hospital and Clinics, Faculty of Medicine, University of São Paulo (IOT-HCFMUSP), São Paulo, Brazil. ${ }^{3}$ Department of Orthopaedic Surgery, Catholic University of São Paulo, Sorocaba, São Paulo, Brazil. ${ }^{4}$ Rua Dr. Ovídio Pires de Campos, 333, Cerqueira Cesar, São Paulo SP CEP: 05403-010, Brazil.

Received: 17 August 2015 Accepted: 26 April 2016

Published online: 30 April 2016

\section{References}

1. Vincent JP, Magnussen RA, Gezmez F, Uguen A, Jacobi M, Weppe F, et al. The anterolateral ligament of the human knee: an anatomic and histologic study. Knee Surg Sports Traumatol Arthrosc. 2012;20:147-52. doi:10.1007/ s00167-011-1580-3.

2. Helito CP, Miyahara HS, Bonadio MB, Tirico LEP, Gobbi RG, Demange MK, et al. Estudo anatômico do ligamento anterolateral do joelho [Anatomical study of the anterolateral knee ligament]. Rev Bras Ortop. 2013;48:368-73. doi:10.1016/j.rbo.2013.04.003

3. Claes S, Vereecke E, Maes M, Victor J, Verdonk P, Bellemans J. Anatomy of the anterolateral ligament of the knee. J Anat. 2013;223:321-8. doi:10.1111/ joa.12087.

4. Helito CP, Demange MK, Bonadio MB, Tirico LEP, Gobbi RG, Pecora JR, et al. Anatomy and histology of the knee anterolateral ligament. Orthop J Sports Med. 2013;1:2325967113513546. doi:10.1177/2325967113513546.

5. Dodds AL, Halewood C, Gupte CM, Williams A, Amis AA. The anterolateral ligament: anatomy, length changes and association with the Segond fracture. Bone Joint J. 2014;96-B:325-31. doi:10.1302/0301-620X.96B3.33033.
6. Caterine S, Litchfield R, Johnson M, Chronik B, Getgood A. A cadaveric study of the anterolateral ligament: re-introducing the lateral capsular ligament. Knee Surg Sports Traumatol Arthrosc 2014. doi: 10.1007/s00167-014-3117-z.

7. Hussein M, van Eck CF, Cretnik A, Dinevski D, Fu FH. Individualized anterior cruciate ligament surgery: a prospective study comparing anatomic singleand double-bundle reconstruction. Am J Sports Med. 2012;40:1781-8. doi: 10.1177/0363546512446928.

8. Hussein M, van Eck CF, Cretnik A, Dinevski D, Fu FH. Prospective randomized clinical evaluation of conventional single-bundle, anatomic single-bundle, and anatomic double-bundle anterior cruciate ligament reconstruction: 281 cases with 3- to 5-year follow-up. Am J Sports Med. 2012;40:512-20. doi:10.1177/0363546511426416.

9. Helito CP, Helito PV, Costa HP, Bordalo-Rodrigues M, Pecora JR, Camanho $G L$, et al. MRI evaluation of the anterolateral ligament of the knee: assessment in routine 1.5T scans. Skeletal Radiol. 2014;43:1421-7. doi:10. 1007/s00256-014-1966-7.

10. Claes S, Bartholomeeusen S, Bellemans J. High prevalence of anterolateral ligament abnormalities in magnetic resonance images of anterior cruciate ligament-injured knees. Acta Orthop Belg. 2014;80:45-9.

11. Helito $C P$, Bonadio MB, Soares $T Q$, da Mota E Albuquerque RF, Natalino RJ Pécora JR, et al. The meniscal insertion of the knee anterolateral ligament. Surg Radiol Anat. 2015. [Epub ahead of print]

12. Helito CP, Demange MK, Bonadio MB, Tirico LE, Gobbi RG, Pecora JR, et al. Radiographic landmarks for locating the femoral origin and tibial insertion of the knee anterolateral ligament. Am J Sports Med. 2014;42:2356-62. doi: 10.1177/0363546514543770.

13. Rezansoff AJ, Caterine S, Spencer L, Tran MN, Litchfield RB, Getgood AM. Radiographic landmarks for surgical reconstruction of the anterolateral ligament of the knee Knee Surg Sports Traumatol Arthrosc. 2014. doi: 10. 1007/s00167-014-3126-y.

14. Helito CP, Helito PV, Bonadio MB, da Mota e Albuquerque RF, BordaloRodrigues $\mathrm{M}$, Pecora JR, et al. Evaluation of the anterolateral ligament length and isometric pattern with serial computer tomography. Orthop J Sports Med. 2014;2:2325967114562205. doi:10.1177/2325967114562205.

15. Monaco E, Ferretti A, Labianca L, Maestri B, Speranza A, Kelly MJ, et al. Navigated knee kinematics after cutting of the ACL and its secondary restraint. Knee Surg Sports Traumatol Arthrosc. 2012;20:870-7. doi:10.1007/ s00167-011-1640-8.

16. Monaco E, Maestri B, Conteduca F, Mazza D, lorio C, Ferretti A. Extra-articular $A C L$ reconstruction and pivot shift: in vivo dynamic evaluation with navigation. Am J Sports Med. 2014;42:1669-74. doi:10.1177/0363546514532336.

17. Zens M, Feucht MJ, Ruhhammer J, Berntein A, Mayr HO, Sudkamp NP, et al. Mechanical tensile properties of the anterolateral ligament. J Exp Orthop. 2015;2:7. doi:10.1186/s40634-015-0023-3.

18. Kennedy MI, Claes S, Fuso FA, Williams BT, Goldsmith MT, Turnbull TL, et al. The anterolateral ligament: an anatomic, radiographic, and biomechanical analysis. Am J Sports Med. 2015:43(7):1606-15.

19. LaPrade RF, Ly TV, Wentorf FA, Engebretsen L. The posterolateral attachments of the knee: a qualitative and quantitative morphologic analysis of the fibular collateral ligament, popliteus tendon, popliteofibular ligament, and lateral gastrocnemius tendon. Am J Sports Med. 2003;31(6): 854-60.

20. Butler PD, Mellecker CJ, Rudert MJ, Albright JP. Single-bundle versus doublebundle $A C L$ reconstructions in isolation and in conjunction with extraarticular iliotibial band tenodesis. lowa Orthop J. 2013;33:97-106.

21. Saragaglia D, Pison A, Refaie R. Lateral tenodesis combined with anterior cruciate ligament reconstruction using a unique semitendinosus and gracilis transplant. Int Orthop. 2013;37:1575-81. doi:10.1007/s00264-013-1957-7.

22. Trichine F, Alsaati M, Chouteau J, Moyen B, Bouzitouna M, Maza R. Patellar tendon autograft reconstruction of the anterior cruciate ligament with and without lateral plasty in advanced-stage chronic laxity. A clinical, prospective, randomized, single-blind study using passive dynamic X-rays. Knee. 2014;21:58-65. doi:10.1016/j.knee.2013.06.001.

23. Dejour D, Vanconcelos W, Bonin N, Saggin PR. Comparative study between mono-bundle bone-patellar tendon-bone, double-bundle hamstring and mono-bundle bone-patellar tendon-bone combined with a modified Lemaire extra-articular procedure in anterior cruciate ligament reconstruction. Int Orthop. 2013;37:193-9. doi:10.1007/s00264-012-1718-z.

24. Duthon VB, Magnussen RA, Servien E, Neyret P. ACL reconstruction and extra-articular tenodesis. Clin Sports Med. 2013;32:141-53. doi:10.1016/j.csm. 2012.08.013. 
25. Vadalà AP, lorio R, De Carli A, Bonifazi A, lorio C, Gatti A, et al. An extraarticular procedure improves the clinical outcome in anterior cruciate ligament reconstruction with hamstrings in female athletes. Int Orthop. 2013;37:187-92. doi:10.1007/s00264-012-1571-0.

26. Edwards DJ, Brown JN, Roberts SN, Paterson RS. Long-term results of anterior cruciate ligament reconstruction using ilio-tibial tract and semitendinosis tendon. Knee. 2000;7:87-93. doi:10.1016/50968-0160(00)00035-1.

27. Wijdicks CA, Ewart DT, Nuckley DJ, Johansen S, Engebretsen L, Laprade RF. Structural properties of the primary medial knee ligaments. Am J Sports Med. 2010;38:1638-46. doi:10.1177/0363546510363465.

28. Herbort M, Hoser C, Domnick C, Raschke MJ, Lenschow S, Weimann A, et al. MPFL reconstruction using a quadriceps tendon graft: part 1: Biomechanical properties of quadriceps tendon MPFL reconstruction in comparison to the intact MPFL. A human cadaveric study. Knee. 2014;21:1169-74. doi:10.1016/j. knee.2014.07.026.

29. Mountney J, Senavongse W, Amis AA, Thomas NP. Tensile strength of the medial patellofemoral ligament before and after repair or reconstruction. J Bone Joint Surg (Br). 2005;87:36-40.

30. Ciccone 2nd WJ, Bratton DR, Weinstein DM, Walden DL, Elias JJ. Structural properties of lateral collateral ligament reconstruction at the fibular head. Am J Sports Med. 2006:34:24-8.

31. Kittl C, Halewood C, Stephen JM, et al. Length change patterns in the lateral extra-articular structures of the knee and related reconstructions. Am J Sports Med. 2015;43(2):354-62.

32. Pearsall 4th AW, Hollis JM, Russell Jr GV, Scheer Z. A biomechanical comparison of three lower extremity tendons for ligamentous reconstruction about the knee. Arthroscopy. 2003;19:1091-6. doi:10.1016/j.arthro.2003.10.015.

33. Noyes FR, Butler DL, Grood ES, Zernicke RF, Hefzy MS. Biomechanical analysis of human ligament grafts used in knee-ligament repairs and reconstructions. J Bone Joint Surg Am. 1984;66:344-52.

34. Helito CP, Bonadio MB, Gobbi RG, da Mota EARF, Pecora JR, Camanho GL, et al. Combined intra- and extra-articular reconstruction of the anterior cruciate ligament: the reconstruction of the knee anterolateral ligament. Arthrosc Tech. 2015;4(3):e239-44.

35. Sonnery-Cottet B, Thaunat M, Freychet B, Pupim BH, Murphy CG, Claes S. Outcome of a combined anterior cruciate ligament and anterolateral ligament reconstruction technique with a minimum 2-year follow-up. Am J Sports Med. 2015:43(7):1598-605.

36. Marcacci M, Zaffagnini S, Giordano G, lacono F, Presti ML. Anterior cruciate ligament reconstruction associated with extra-articular tenodesis: A prospective clinical and radiographic evaluation with 10- to 13-year follow-up. Am J Sports Med. 2009;37:707-14.

37. Mariscalco MW, Flanigan DC, Mitchell J, Pedroza AD, Jones MH, Andrish JT, et al. The influence of hamstring autograft size on patient-reported outcomes and risk of revision after anterior cruciate ligament reconstruction: a multicenter orthopaedic outcomes network (MOON) cohort study. Arthroscopy. 2013;29:1948-53. doi:10.1016/j.arthro.2013.08.025.

38. Russ SD, Tompkins M, Nuckley D, Macalena J. Biomechanical comparison of patellar fixation techniques in medial patellofemoral ligament reconstruction. Am J Sports Med. 2014. doi:10.1177/0363546514550992.

39. Angelini FJ, Helito CP, Tozi MR, Pozzobon L, Bonadio MB, Gobbi RG, et al. Combined reconstruction of the anterior cruciate ligament and posterolateral corner with a single femoral tunnel. Arthrosc Tech. 2013;2:e285-8.

40. Gali JC, Bernardes AD, Dos Santos LC, Ferreira TC, Almagro MA, da Silva PA. Tunnel collision during simultaneous anterior cruciate ligament and posterolateral corner reconstruction. Knee Surg Sports Traumatol Arthrosc. 2014. doi:10.1007/s00167-014-3363-0.

41. Helito CP, Bonadio MB, Gobbi RG, da Mota E Albuquerque RF, Pécora JR, Camanho GL, et al. Is it safe to reconstruct the knee Anterolateral Ligament with a femoral tunnel? Frequency of Lateral Collateral Ligament and Popliteus Tendon injury. Int Orthop. 2015. [Epub ahead of print]

42. Claes S, Luyckx T, Vereecke E, Bellemans J. The Segond fracture: a bony injury of the anterolateral ligament of the knee. Arthroscopy. 2014. doi:10. 1016/j.arthro.2014.05.039

43. Terry GC, LaPrade RF. The biceps femoris muscle complex at the knee. Its anatomy and injury patterns associated with acute anterolateralanteromedial rotatory instability. Am J Sports Med. 1996;24(1):2-8.

44. De Maeseneer M, Boulet C, Willekens I, Lenchik L, De Mey J, Cattrysse E, Shahabpour M. Segond fracture: involvement of the iliotibial band, anterolateral ligament, and anterior arm of the biceps femoris in knee trauma. Skeletal Radiol. 2015;44(3):413-21.

\section{Submit your next manuscript to BioMed Central and we will help you at every step:}

- We accept pre-submission inquiries

- Our selector tool helps you to find the most relevant journal

- We provide round the clock customer support

- Convenient online submission

- Thorough peer review

- Inclusion in PubMed and all major indexing services

- Maximum visibility for your research

Submit your manuscript at www.biomedcentral.com/submit
Biomed Central 